\title{
COMPUTATIONAL ANALYSIS OF COMPOUNDS FROM OCIMUM SANCTUM FOR ANTICANCER ACTIVITY AGAINST ORAL SQUAMOUS CELL CARCINOMA
}

\author{
ARIYA SS $^{1,3 *}$, BABY JOSEPH ${ }^{2}$, SANTHANAM VIJAYASRI ${ }^{3}$, WAHEETA HOPPER ${ }^{3}$
}

${ }^{1}$ Department of Biotechnology, Hindustan Institute of Technology and Science, Chennai, Tamil Nadu, India. ${ }^{2}$ Department of Research, Hindustan Institute of Technology and Science, Chennai, Tamil Nadu, India. ${ }^{3}$ Department of Biotechnology, Faculty of Engineering and Technology, SRM Institute of Science and Technology, Kattankulathur, Tamil Nadu, India. Email: ariyass1992@gmail.com

Received: 19 July 2018, Revised and Accepted: 11 September 2018

\section{ABSTRACT}

Objective: The objectives of this research are to identify the potentials of active phytochemicals from Ocimum sanctum as anticancer agents, by inhibiting the epidermal growth factor receptor (EGFR), one of the highly expressed proteins inducing metastasis in oral squamous cell carcinoma (OSCC) as well as other cancers.

Methods: The phytochemicals found in 0 . sanctum were identified and downloaded from online chemical databases. The target protein was retrieved from the Protein Data Bank. Virtual screening using glide protocols of high throughput virtual screening and molecular docking using standard precision and extra precision (XP) were carried out. The binding energies and the important physicochemical properties of the compounds were also determined.

Results: A total number of 210 compounds from 0 . sanctum were screened against EGFR. Lipinski rule was followed to find the compounds with favorable drug absorptive properties. The shortlisted compounds, namely luteolin, apigenin, and isothymusin, possess high Glide scores (kcal/mol) of $-9.98,-9.51$, and -9.45 and binding energies $(\mathrm{kcal} / \mathrm{mol})$ of $-42.63,-48.28$, and -44.95 , respectively.

Conclusion: Among the three compounds, Isothymusin was not yet been reported to posess anticancer activity. Our study suggest this compound as a potential chemotherapeutic agent for treating OSCC. They function by inhibiting the activity of metastasis - inducing protein EGFR.

Keywords: Ocimum sanctum, Phytochemicals, Oral squamous cell carcinoma, Epidermal growth factor receptor, Docking, Binding energy and Lipinski rule.

(C) 2019 The Authors. Published by Innovare Academic Sciences Pvt Ltd. This is an open access article under the CC BY license (http://creativecommons. org/licenses/by/4. 0/) DOI: http://dx.doi.org/10.22159/ajpcr.2019.v12i1.28575

\section{INTRODUCTION}

\section{Oral squamous cell carcinoma (OSCC)}

Cancer is one of the leading causes of death worldwide [1]. Among all the cancers, oral cancer is most commonly diagnosed, especially in developing countries [2]. OSCC is one of the most leading cancercausing deaths. Although several treatment options are available for cancer, a promising one is yet to be identified as the already available ones are either not effective or they cause side effects.

\section{Cancer and epidermal growth factor receptor (EGFR)}

Oral cancer is the sixth most common cancer worldwide [3]. In the majority of the OSCC cases, an association of EGFR (EGFR/ErB1/HER1) has been reported in promoting aggressiveness, metastasis, poor prognosis, as well as anticancer therapy resistance [4]. This protein has also been found to be expressed in several other cancers as well. EGFR is a tyrosine kinase receptor which belongs to the family of ErbB and is a receptor of EGF as well as transforming growth factor alpha. Resistance to chemotherapeutic agents used in treating OSCC was found to be associated with higher expression of EGFR. They showed resistance against drugs such as 5-fluorouracil, cisplatin, doxorubicin, and cyclophosphamide. Cetuximab is the FDA approved drug presently used in treating cancer by inhibiting EGFR [5]. However, these drugs cannot be considered an outstanding one and are effective only as a first-line treatment option in combination with platinum [6].

\section{Ocimum sanctum}

"Return to Nature" is nowadays a trend [7]. Medicinal plants have been used since long time for curing several disease. This is because the plants are a prominent hub of a wide variety of active chemicals. To meet their primary health-care needs, most of the developing and underdeveloped countries in the world depend on plants as a source of medicine. One such plant is $O$. sanctum Linn. commonly called as tulsi or holy basil whose entire part possesses medicinal properties. It is considered as the "queen of herbs." They are used in treating several ailments which even include cancers [8]. Hence, for this study, the phytochemicals from O. sanctum were selected for screening against EGFR.

\section{Classification of $O$. sanctum}

- Kingdom: Plantae.

- Subkingdom: Viridiplantae.

- Infrakingdom: Streptophyta.

- Superdivision: Embryophyta.

- Phylum: Tracheophyta.

- Subdivision: Spermatophytina.

- Class: Magnoliopsida.

- Superorder: Asteranae.

- Order: Lamiales.

- Family: Lamiaceae.

- Genus: Ocimum.

- Species: O. sanctum.

\section{METHODS}

Phytochemical detection and structure retrieval

The phytochemicals present in the plant $O$. Sanctum were determined in two ways. One was through the literature survey of published research articles related to chemical constituents of 0 . sanctum [6-15] 
and the other one by querying phytochemical databases. Along with this, Dr. Duke's Phytochemical and Ethnobotanical Databases of the United States Department of Agriculture [16] which provided the indepth knowledge regarding the phytochemicals, as well as bioactivity of the plant, was also used for collecting the data. A total of 14 compounds from Dr. Duke's Phytochemical and Ethnobotanical Databases and 196 unique compounds (excluding those reported in the database) were identified. The chemical structure of these compounds for docking was retrieved from PubChem database hosted by the National Center for Biotechnology Information [17]. Those structures which were not available with PubChem were retrieved from the ChemSpider database of Royal Society of Chemistry [18].

\section{Retrieval of target structure and docking}

The target structure of EGFR with PDB ID: 5X2C was retrieved from Protein Data Bank. It belongs to the classification of transferase proteins of Homo sapiens. The three-dimensional structure was determined by X-ray diffraction method. It is with a resolution of $2.05 \AA$. The structure is with two chains, whereas the cocrystal ligand showed interaction with the chain A. The cocrystal ligand is 9-cyclopentyl-N2-[4-(4methyl piperazine-1-yl) phenyl]-N8-phenyl-purine-2,8-diamine. The molecular formula of this ligand is C27 H32 N8 [19].

\section{Protein and ligand preparations}

Protein preparation was carried out by removing the water molecules present with the crystallized structure of the target. Ligand preparation was also carried out. This ensures the conversion of the ligand format into a single format accessible by Maestro for virtual screening [20].

\section{Generation of grid}

The binding site is a specific area of the target protein to which the ligands are made to interact during docking. Specifying the binding site of the target protein is one of the important steps that aid docking [21]. For the current study, binding site to which the cocrystal ligand bound was determined and selected. Based on this, a grid was generated and docking was carried out.

\section{Docking}

The three-dimensional structure of the target protein EGFR (5X2C) was docked with the 210 unique ligands from 0 . sanctum using Glide protocol in Maestro Schrodinger, commercial software for molecular modeling and visualization program for drug design and material science. Based on the Lipinski rule, the compounds were screened and only those compounds that satisfied the Lipinski rule were further used for docking to maximize the screening yield with favorable pharmacokinetic properties [22,23]. Three different virtual screening methods were adapted to improve the precision of the result. They include high throughput virtual screening (HTVS), standard precision (SP), and extra precision (XP) [24-26]. The binding energies were also calculated.

\section{Interaction analysis}

After docking, the interaction of the ligands with the target molecule in the active site was analyzed. Bonded and non-bonded interactions made by the ligands with the target protein that ensures the strength of the binding were viewed and analyzed.

\section{RESULTS}

\section{HTVS of compounds}

Structure-based ligand and protein interaction were carried out using Maestro Schrodinger. Three different docking protocols were adapted to ensure and screen the best fitting ligand. The entire dataset of compounds was first subjected to HTVS protocol of Glide docking. It screened the entire set of 210 compounds. Of these compounds, only 35 of them possessed better Glide scores.

\section{SP docking}

From the resultant ligands of HTVS, 30\% of the high scoring compounds were then taken for further docking. These ligands were then subjected to SP docking of Glide. As a result, only 35 compounds were finalized as best fit molecules with the target structure. The name of each phytochemical with their Glide scores and binding energy by HTVS as well as SP is interpreted in Table 1.

\section{XP docking}

After HTVS and SP docking, XP docking was carried out with the shortlisted compounds. The phytochemicals, namely apigenin, luteolin, and isothymusin, from $O$. sanctum were considered as the best hits against EGFR, during this last stage of docking. They possess high Glide scores $(\mathrm{kcal} / \mathrm{mol})$ of $-9.98,-9.52$, and -9.45 , respectively. The Glide scores and binding energies of the best hits are shown in Table 2 .

\section{Interaction of apigenin with EGFR}

The compound apigenin showed strong interaction with the binding pocket of the protein EGFR. There were two hydrogen bonds formed between Met 793 with the $\mathrm{OH}$ and $\mathrm{O}$ groups of the compound. Similarly, two other hydrogen bonds occurred between two $\mathrm{OH}$ groups of the ligand with the amino acid Asp 855 in the protein. It formed nonbonded interactions with other amino acids in the binding site. Fig. 1 shows the three-dimensional image of the interaction of apigenin with the binding pocket of EGFR. Fig. 2 shows the two-dimensional (2D) representation of the interaction of this ligand with the amino acid residues of the protein EGFR.

\section{Interaction of luteolin with EGFR}

Luteolin formed two hydrogen bonds with Met 793 and Asp 855 using its hydroxyl groups. Both of the interactions are through a hydrogen bond formed between the amino acids and atoms in the molecule. The non-bonded interactions were observed with all other amino acids in

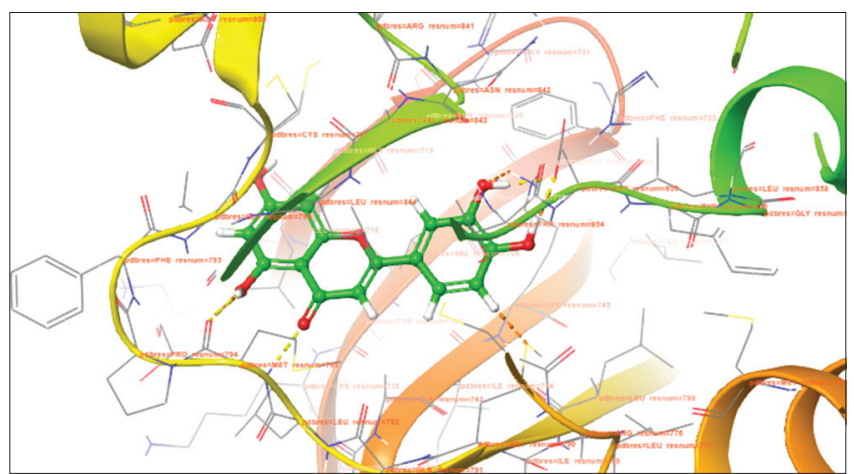

Fig. 1: Three-dimensional representation of the interactions of apigenin with epidermal growth factor receptor at its binding site

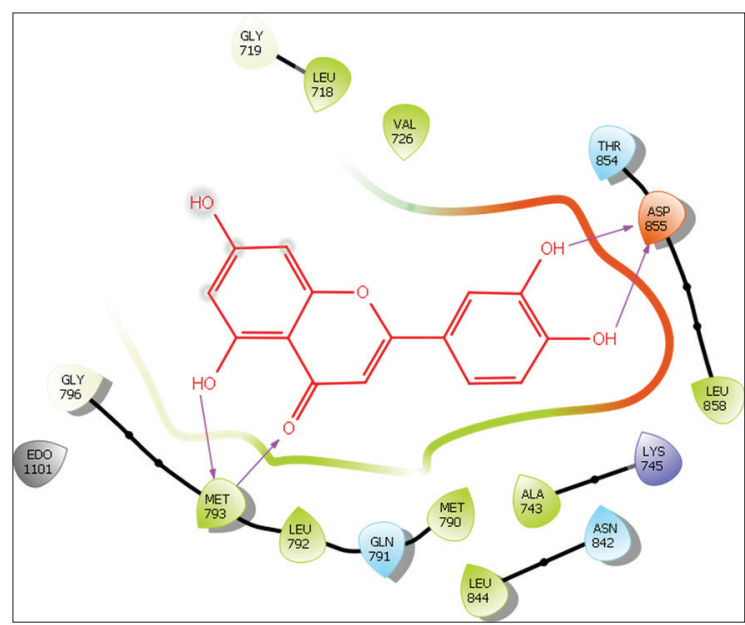

Fig. 2: Two-dimensional representation of epidermal growth factor receptor and apigenin interactions showing hydrogen bonds 
Table 1: Glide scores and binding energy of compounds which showed better interaction with target 5X2C in virtual screening (HTVS and SP) with their important physicochemical properties

\begin{tabular}{|c|c|c|c|c|c|c|c|c|c|}
\hline \multirow[t]{2}{*}{ S. No. } & \multirow[t]{2}{*}{ Compound name } & \multicolumn{2}{|c|}{$\begin{array}{l}\text { Glide score } \\
\text { (kcal/mol) }\end{array}$} & \multicolumn{2}{|c|}{$\begin{array}{l}\text { Binding energy } \\
\text { (kcal/mol) }\end{array}$} & \multirow[t]{2}{*}{$\begin{array}{l}\text { Mol. } \\
\text { weight }\end{array}$} & \multirow[t]{2}{*}{ Acceptor } & \multirow[t]{2}{*}{ Donor } & \multirow[t]{2}{*}{$\log P$} \\
\hline & & HTVS & SP & HTVS & SP & & & & \\
\hline 1. & Apigenin & -7.57 & -8.18 & -47.68 & -45.73 & 286.23 & 6 & 4 & 0.96 \\
\hline 2. & Luteolin & -7.56 & -9.09 & -43.84 & -43.56 & 270.24 & 5 & 3 & 1.64 \\
\hline 3. & $\begin{array}{l}\text { 5-hydroxy-2-(4-hydroxy-3-methoxy-phenyl)-6,7- } \\
\text { dimethoxy-chromone }\end{array}$ & -7.41 & -8.86 & -46.36 & -50.09 & 344.31 & 7 & 2 & 2.88 \\
\hline 4. & Phenanthrene & -7.25 & -7.26 & -27.32 & -27.32 & 178.23 & 0 & 0 & 4.46 \\
\hline 5. & $\begin{array}{l}\text { (8R,9S,13S,14S,17S)-13-methyl-6,7,8,9,11,12,14,15,16,17- } \\
\text { decahydrocyclopenta[a] phenanthrene-3,17-diol }\end{array}$ & -7.06 & -7.00 & -34.89 & -36.01 & 272.38 & 2 & 2 & 4.00 \\
\hline 6. & Isothymusin & -7.06 & -8.60 & -49.34 & -47.38 & 330.29 & 7 & 3 & 2.06 \\
\hline 7. & 5-hydroxy-2-(4-hydroxyphenyl)-6,7-dimethoxy-chromone & -6.04 & -8.73 & -41.44 & -46.17 & 314.29 & 6 & 2 & 2.68 \\
\hline 8. & 4-(4-carboxyphenyl) benzoic acid & -6.98 & -7.73 & -29.34 & -32.84 & 242.23 & 4 & 2 & 2.24 \\
\hline 9. & Benzoic acid benzyl ester & -6.92 & -7.58 & -31.38 & -34.10 & 212.24 & 2 & 0 & 3.55 \\
\hline 10. & (1R,4S)-1-isopropyl-4-methyl-bicyclo[3.1.0]hexan-4-ol & -6.78 & -4.67 & -15.53 & -18.73 & 154.25 & 1 & 1 & 2.68 \\
\hline 11. & 2-ethyl-1- $\$ 1^{\wedge}\{1\}$-oxidanyl-2-phenyl-pseudoindoxyl & -6.72 & -6.83 & -28.49 & -30.86 & 252.29 & 2 & 0 & 2.02 \\
\hline 12. & 6-methoxy-3-methyl-benzofuran & -6.58 & -6.72 & -24.62 & -24.72 & 162.18 & 2 & 0 & 2.65 \\
\hline 13. & Carvacrol & -6.53 & -7.28 & -23.67 & -25.22 & 150.22 & 1 & 1 & 3.29 \\
\hline 14. & 1-isopropyl-4-methyl-cyclohex-3-en-1-ol & -6.43 & -6.44 & -17.70 & -25.22 & 154.25 & 1 & 1 & 2.95 \\
\hline 15. & $\begin{array}{l}\text { (1aR,4R,4aR,7R,7aS,7bS)-1,1,4,7-tetramethyl-2,3,4a, } \\
\text { 5,6,7,7a, 7b-octahydro-1aH-cycloprop[e] azulen-4-ol }\end{array}$ & -6.39 & -6.29 & -25.82 & -28.08 & 222.37 & 1 & 1 & 3.88 \\
\hline 16. & $\begin{array}{l}4,6,6,7,8,8 \text {-hexamethyl-1,3,4,7-tetrahydrocyclopent }[\mathrm{g}] \\
\text { isochromene }\end{array}$ & -6.36 & -6.45 & -31.67 & -29.97 & 258.40 & 1 & 0 & 3.47 \\
\hline 17. & (1R,4aR,7R,8aR)-7-isopropenyl-1,4a-dimethyl-decalin-1-ol & -6.24 & -6.45 & -30.29 & -31.63 & 222.37 & 1 & 1 & 3.96 \\
\hline 18. & 2-(4-methylcyclohex-3-en-1-yl) propan-2-ol & -6.08 & -5.06 & -22.19 & -22.85 & 154.25 & 1 & 1 & 2.94 \\
\hline 19. & 1-isopropyl-4-methyl-cyclohexa-1,3-diene & -6.07 & -5.82 & -19.42 & -18.69 & 136.23 & 0 & 0 & 4.05 \\
\hline 20. & 1-acetyl-2-pyrrolidone & -5.99 & -6.57 & -21.49 & -21.27 & 127.14 & 2 & 0 & 0.20 \\
\hline 21. & 5-isopropyl-2-methyl-cyclohexa-1,3-diene & -5.90 & -5.81 & -17.95 & -19.03 & 136.23 & 0 & 0 & 4.01 \\
\hline 22. & Naphthalene & -5.84 & -6.08 & -20.32 & -20.29 & 128.17 & 0 & 0 & 3.35 \\
\hline 23. & p-cymene & -5.80 & -5.56 & -19.74 & -20.45 & 134.22 & 0 & 0 & 3.67 \\
\hline 24. & (5R)-5-isopropyl-2-methyl-cyclohexa-1,3-diene & -5.75 & -5.73 & -18.02 & -18.86 & 136.23 & 0 & 0 & 3.99 \\
\hline 25. & $\begin{array}{l}\text { (1S,4E,8E,10R)-4,8,11,11-tetramethylbicyclo[8.1.0] } \\
\text { undeca-4,8-diene }\end{array}$ & -5.67 & -4.27 & -20.00 & -22.60 & 204.35 & 0 & 0 & 4.98 \\
\hline 26. & 1-isopropyl-4-methylene-bicyclo[3.1.0]hexane & -5.62 & -5.68 & -14.93 & -16.16 & 136.23 & 0 & 0 & 3.79 \\
\hline 27. & 4-isopropylidene-1-methyl-cyclohexene & -5.58 & -5.64 & -18.53 & -20.45 & 136.23 & 0 & 0 & 4.20 \\
\hline 28. & 1-isopropyl-4-methyl-cyclohexa-1,4-diene & -5.56 & -5.82 & -18.32 & -18.69 & 136.23 & 0 & 0 & 4.03 \\
\hline 29. & Phthalic acid & -5.56 & -6.74 & -17.34 & -23.98 & 166.13 & 4 & 2 & 0.77 \\
\hline 30. & Eugenol & -5.54 & -5.78 & -25.57 & -27.01 & 164.20 & 2 & 1 & 2.73 \\
\hline 31. & pentan-2-one & -5.40 & -4.93 & -14.64 & -15.67 & 86.13 & 1 & 0 & -1.20 \\
\hline 32. & 2-methoxy-4-[(E)-prop-1-enyl] phenol & -5.37 & -6.09 & -24.74 & -26.22 & 164.20 & 2 & 1 & 2.86 \\
\hline 33. & Camphor & -5.29 & -4.91 & -13.11 & -21.48 & 152.23 & 1 & 0 & 1.93 \\
\hline 34. & 2,2-dimethyl-3-methylene-norbornane & -5.24 & -5.61 & -15.44 & -17.68 & 136.23 & 0 & 0 & 3.24 \\
\hline 35. & (3R,4S,5R)-tetrahydropyran-2,3,4,5-tetrol & -5.20 & -5.60 & -26.82 & -28.55 & 150.13 & 5 & 4 & -1.66 \\
\hline
\end{tabular}

Donor: Number of hydrogen bond donors, Acceptor: Number of hydrogen bond acceptors, HTVS: High throughput virtual screening, SP: Standard precision

the binding pocket. Fig. 3 shows the interaction of the drug molecule luteolin with the binding pocket of EGFR. Fig. 4 is a 2D representation of the drug and amino acid of EGFR interaction.

\section{Isothymusin and EGFR interaction}

The interaction of amino acids of EGFR with the flavonolic compound was also facilitated by the formation of hydrogen bonds as depicted in Figs. 5 and 6. Here, a total number of three hydrogen bonds were formed between the ligand and the amino acids of the protein molecule. There were two hydrogen bonds with Met 793 using its $\mathrm{OH}$ and $\mathrm{O}$ groups and a hydrogen bond with Asp 855 using its $\mathrm{OH}$ group. The non-bonded interactions dominated the binding.

\section{DISCUSSION}

The XP docking paved the way for the identification of three active compounds to possess anticancer activity in a higher level than that of the remaining other phytochemicals. Luteolin and apigenin are the drugs which have been already tested to prove their efficacy both in vitro and in vivo. It is proved that luteolin prevents tumor development largely by inactivating several signals and transcription pathways essential for cancer cells [27]. Luteolin belonging to the family of flavonoids
Table 2: The Glide scores and binding energies of the best hits from $O$. sanctum calculated using XP docking

\begin{tabular}{llll}
\hline S. No. & Compound & $\begin{array}{l}\text { Glide score } \\
\text { (kcal/mol) }\end{array}$ & $\begin{array}{l}\text { Glide energy } \\
\text { (kcal/mol) }\end{array}$ \\
\hline 1. & Apigenin & -9.98 & -42.63 \\
2. & Isothymusin & -9.52 & -48.28 \\
3. & Luteolin & -9.45 & -44.95 \\
\hline
\end{tabular}

O. sanctum: Ocimum sanctum, XP: Extra precision

is a potential anticancer agent targeting oral cancer cells along with metixene hydrochloride and nitazoxanide. This compound is found to exhibit low cytotoxicity with high efficiency when compared with other anticancer drugs such as cisplatin and tyrphostin [28]. Luteolin was also found to reduce the viability of SCC-4 cells and induced apoptosis. This is ensured by decreasing the expression of cyclin-dependent kinase (CDKs), cyclins, and phosphor-retinoblastoma antiapoptotic protein. This then increased the expression of proapoptotic proteins and activated caspase 9 and 3, with a concomitant increase in the levels of cleaved poly-ADP-ribose polymerase [29]. 


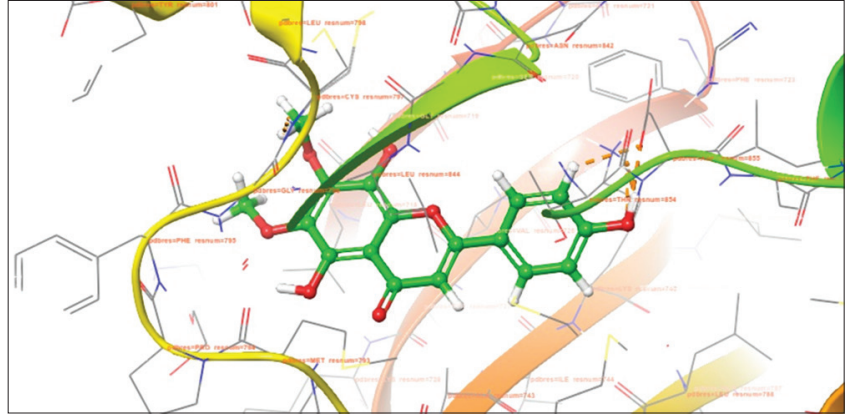

Fig. 3: Three-dimensional representation of the interaction of luteolin with epidermal growth factor receptor

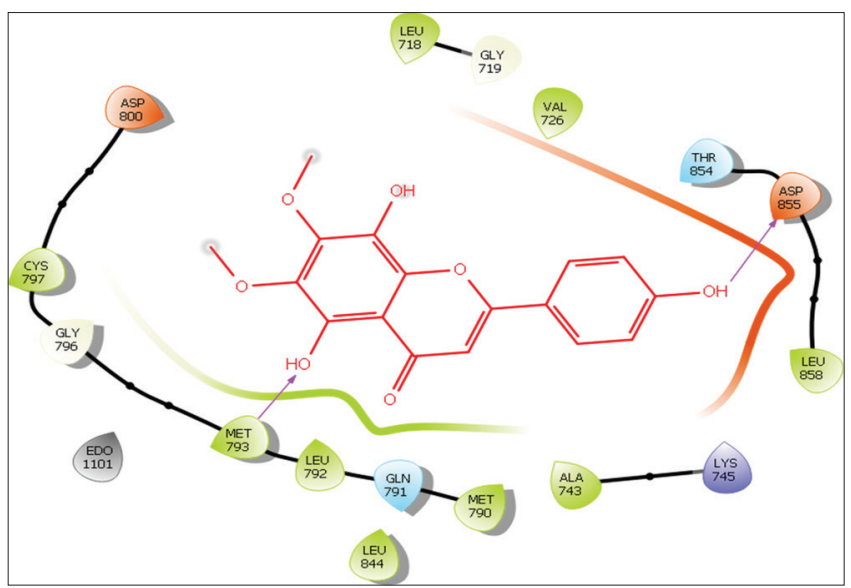

Fig. 4: Two-dimensional representation of the interaction of luteolin with binding site amino acids of epidermal growth factor receptor

Apigenin, chemically known as 4', 5, 7-trihydroxyflavone, belongs to the family of flavone [30]. Apigenin was classified as a Class II drug of Biopharmaceutical Classification System in a recent study [31]. When OSCC cell line SCC-25 was treated with apigenin, it leads to the arrest of the cell cycle in both G0/G1 and G2/M checkpoints. This is associated with decreased expression of cyclin D1 and E, and inactivation of CDK1 [32]. HNSCC cell lines such as CAL-27 and SCC-15 were treated with apigenin and proved the efficiency of this compound in inducing cancer healing by inhibiting survival and inducing apoptosis of the cells. It is also found that it reduces ligand-induced phosphorylation of EGFR and ErbB2 and impairs their downstream signaling [33].

The novel flavonolic compound isothymusin identified by the current study was also highly competitive with the above said two compounds. The binding energy, as well as the glide score, was also competitive with the remaining two drugs. Hence, it is evident from the analysis that the compound isothymusin can also be used as an anticancer agent for inhibiting EGFR expression.

\section{CONCLUSION}

The XP docking analysis of compounds from 0 . sanctum screened three best compounds as the better inhibitors of EGFR. Among the three compounds suggested by docking, two of them, namely luteolin and apigenin, were already reported to be anticancerous. The studies through in vitro and in vivo methods suggest the potency of these two compounds as high or equally important to the currently used drugs. This further validates the docking program. The anticancer properties of isothymusin have not been proven yet. As it is showing similarities with the other two compounds, this can also be a potential anticancer drug. Its anticancer activity and the interactions with EGFR were predicted using this study.

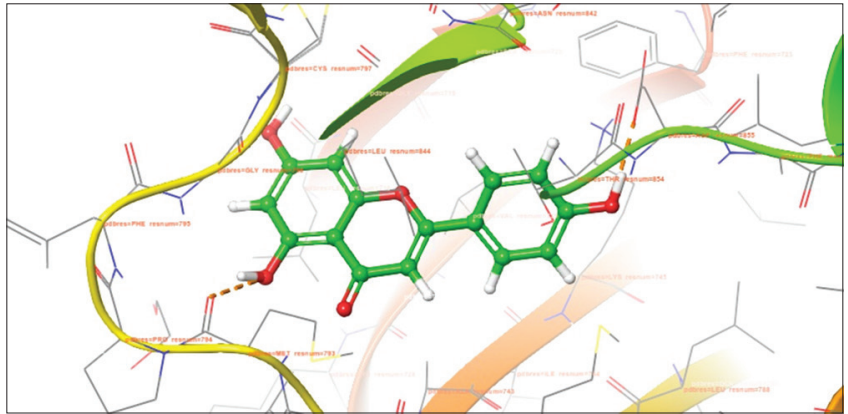

Fig. 5: Interaction of isothymusin with epidermal growth factor receptor in three-dimensional image

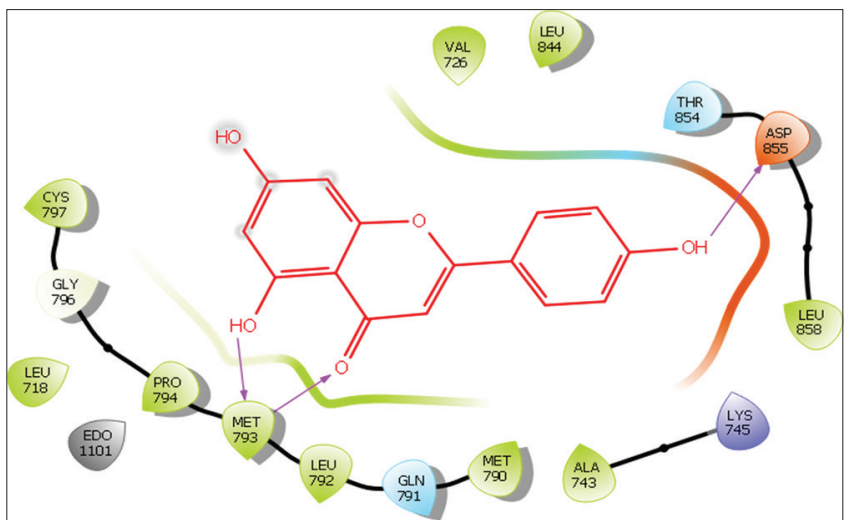

Fig. 6: Two-dimensional representation of the interaction of isothymusin with amino acids of epidermal growth factor receptor by hydrogen bonding

\section{AUTHORS' CONTRIBUTION}

Each author has contributed to the best of their knowledge for the research work carried out in this article.

\section{CONFLICTS OF INTEREST}

The authors declared that they have no conflicts of interest.

\section{REFERENCES}

1. Sridhar PG, Harikiran L, Appa RA, Narsimha RY. Evaluation of anticancer activity of dikamaliartane-a, a cycloartane isolated from dikamalia, a gum resin. Int J Pharm Pharm Sci 2012;4:501-4.

2. Gayathri R, Anuradha V, Vishnupriya V, Mallika J. Anticancer study of Myristica fragrans houtt. (MACE) extract on 4-nitroquinoline-1-oxideinduced oral cancer in rats. Asian J Pharm Clin Res 2018;11:189-92.

3. Ribeiro FA, Noguti J, Oshima CT, Ribeiro DA. Effective targeting of the epidermal growth factor receptor (EGFR) for treating oral cancer: A promising approach. Anticancer Res 2014;34:1547-52.

4. Vanessa FB, Frederico O, Gleber N, Sílvia FS, Rafael MR, Maria CF. EGFR status in oral squamous cell carcinoma: Comparing immunohistochemistry, FISH and CISH detection in a case series study. BMJ Open 2013;3:e002077.

5. Ashish M, Balasundari S, Mala K, Arun S, Abhishek S, Ashutosh A. Epidermal growth factor receptor protein: A biological marker for oral precancer and cancer. J Dent Surg 2014;158709:1-7.

6. Ashraf K, Mark J. Jameson. The EGFR inhibitor gefitinib enhanced the response of human oral squamous cell carcinoma to cisplatin in vitro. Drugs R D 2017:17:545-55.

7. Mainasara MM, Abu Bakar MF, Linatoc AC. Malaysian medicinal plants' potential for breast cancer therapy. Asian J Pharm Clin Res 2018;11:101-17.

8. Prakash P, Neelu G. Therapeutic uses of Ocimum sanctum Linn (Tulsi) with a note on eugenol and its pharmacological actions: A short review. Indian J Physiol Pharmacol 2005;49:125-31.

9. Chil NI, Escalona AJ, Berenguer RC, Mendonça PM, Mateo PK, Dutok SC, et al. Chemical composition and toxicity of Ocimum 
sanctum L. Var. Cubensis essential oil up-growing in the eastern of Cuba. Int J Pharmacogn Phytochem Res 2017;9:1021-8.

10. Dev1 N, Das AK, Hossain MA, Rahman SM. Chemical compositions of different extracts of Ocimum basilicum leaves. J Sci Res 2011;3:197-6.

11. Priyabrata P, Pritishova B, Debajyoti D, Sangram KP. Ocimum sanctum Linn. A reservoir plant for therapeutic applications: An overview. Pharmacogn Rev 2010;4:95-5.

12. Bano N, Ahmed A, Tanveer M, Khan GM, Ansari MT. Pharmacological evaluation of Ocimum sanctum. J Bioequiv Availab 2017;3:387-92.

13. Devesh T, Sah AN, Pandey HK, Meena HS. A review on phyto constituents of Ocimum (Tulsi). Int J Ayurvedic Med 2012;3:1-9.

14. Verma S. Chemical constituents and pharmacological action of Ocimum sanctum (Indian holy basil-Tulsi). J Phytopharmacol 2016;5:205-7.

15. Sumit N, Rana AC, Vinita T, Shaveta G, Ramica S. Review on chemical constituents and pharmacological action of Ocimum kilimandscharicum. Indo Glob J Pharm Sci 2011;1:287-93.

16. Dukes CE. Phytochemical and Ethnobotanical Databases. Available from: http://www.ars-grin.gov/duke.

17. Kim S, Thiessen PA, Bolton EE, Chen J, Fu G, Gindulyte A, et al. PubChem substance and compound databases. Nucleic Acids Res 2016;44:1202-13.

18. Pence HE, Williams A. Chemspider. An online chemical information resource. J Chem Educ 2010;87:1123-4.

19. Zhu SJ, Zhao P, Yang J, Ma R, Yan XE, Yang SY, et al. Structural insights into drug development strategy targeting EGFR T790M/ C797S. Oncotarget 2018;10:9-17.

20. Sastry GM, Matvey AT, Day RA, Woody S. Protein and ligand preparation: Parameters, protocols, and influence on virtual screening enrichments. J Comp Aid Mol Des 2013; 3:221-34.

21. Noeris KS, Roberto N, Woody S. Novel method for generating structure-based pharmacophores using energetic analysis. J Chem Inf Mod 2009;49:2356-68
22. Lipinski CA, Lombardo F, Dominy BW, Feeney PJ. Experimental and computational approaches to estimate solubility and permeability in drug discovery and development settings. Adv Drug Deliv Rev 2011;46:3-26.

23. Lipinski CA. Lead-and drug-like compounds: The rule-of-five revolution. Drug Disc Today Technol 2004;1:337-41.

24. Dixon JS, Blaney JM. Docking Predicting the Structure and Binding Affinity of Ligand Receptor Complexes in Designing Bioactive Molecules. In: Martin YC, Willet P, editors. Washington: American Chemical Society; 1998. p. 175-97.

25. Stahl M. Structure-based library design in virtual screening for bioactive molecules. In: Schneider G, Boehm HJ, editors. Virtual Screening for Bioactive Molecules. $2^{\text {nd }}$ ed. Weinheim: VCH; 2000. p. 229-59.

26. Muegge I, Rarey M. Small molecule docking and scoring. In: Lipkowitz KB, Boyd DB editors. Reviews in Computational Chemistry. $2^{\text {nd }}$ ed. New York: VCH; 2001. p. 1-12.

27. Tuorkey MJ. Molecular targets of luteolin in cancer. Eur J Cancer Prev 2016;25:65-76.

28. Tjioe KC, Tostes OD, Gavard J. Luteolin impacts on the DNA damage pathway in oral squamous cell carcinoma. Nutr Cancer 2016;68:838-47.

29. Yang SF, Yang WE, Chang HR, Chu SC, Hsieh YS. Luteolin induces apoptosis in oral squamous cancer cells. J Dent Res 2008;87:401-6.

30. Miao Qi, Pengfei Li, Yihong Z, Huanjie S. Apigenin in cancer therapy: Anti-cancer effects and mechanisms of action. Cell Biosci 2017;7:1-16.

31. Zhang J, Liu D, Huang Y, Gao Y, Qian S. Biopharmaceutics classification and intestinal absorption study of apigenin. Int J Pharm 2012;436:311-7.

32. Maggioni D, Garavello W, Rigolio R, Pignataro L, Gaini R, Nicolini G. Apigenin impairs oral squamous cell carcinoma growth in vitro inducing cell cycle arrest and apoptosis. Int J Oncol 2013;43:1675-82.

33. Masuelli L, Marzocchella L, Quaranta A, Palumbo C, Pompa G, Izzi V, et al. Apigenin induces apoptosis and impairs head and neck carcinomas EGFR/ErbB2 signalling. Front Biosci 2011;16:1060-8. 